\title{
O direito administrativo como
} caixa de ferramentas e suas estratégias*

\section{The administrative law as a toolbox and its strategies}

\author{
Leonardo Coelho Ribeiro**
}

\section{RESUMO}

Este artigo busca contribuir para a aproximação do direito administrativo com o seu emprego prático e os resultados que produz, enquanto instrumento para a realização de finalidades predefinidas. Para isso, são investigadas não só interfaces do direito administrativo com a economia e a ciência política mas, principalmente, com a ciência da administração. O direito administrativo é, então, tomado pela metáfora de uma caixa de ferramentas, que congrega instrumentos com diferentes

* Artigo recebido em 18 de outubro de 2015 e aprovado em 13 de março de 2016. DOI: http:// dx.doi.org/10.12660/rda.v272.2016.64303.

Este artigo é fruto do livro $O$ direito administrativo como caixa de ferramentas, que se encontra no prelo, a ser publicado pela editora Malheiros.

** Universidade do Estado do Rio de Janeiro, Rio de Janeiro, Rio de Janeiro, Brasil. E-mail: leonardo.coelho@lllaw.com.br.

Mestre em direito público pela Uerj. Especialista em litígios e soluções alternativas de conflitos pela FGV Direito Rio (LL.M Litigation). Coordenador técnico do LL.M em direito da infraestrutura e do Curso de Regulação da Infraestrutura e dos Recursos Naturais no Ibmec (RJ). Professor convidado da FGV Direito Rio e da Emerj. Membro da Comissão de Direito Administrativo da OAB/RJ, IAB e Idaerj. Advogado. 
capacidades, conferindo-se importância ao desenho dos arranjos jurídicos, orientando a seleção, combinação e manejo das ferramentas de direito administrativo segundo os incentivos que podem gerar para cumprir as tarefas pretendidas. As estratégias do direito administrativo como caixa de ferramentas são exploradas após situar o papel do direito diante do processo de seleção de ferramentas sob as óticas da política e da gestão pública, fixando uma estratégia diagnóstica, para avaliar a consistência de arranjos jurídicos em curso, e uma estratégia prognóstica, para projetar combinações de ferramentas que produzam incentivos adequados. Essas estratégias são potencializadas por meio de uma associação aos métodos de experimentalismo, incrementalismo e minimalismo institucional.

\section{PALAVRAS-CHAVE}

Direito administrativo - economia - ciência política - ciência da administração - tecnologia social - instrumentalismo jurídico - caixa de ferramentas - incentivos - diagnóstico - prognóstico - experimentalismo - incrementalismo - minimalismo institucional

\section{ABSTRACT}

This study seeks to contribute to the approximation of Administrative Law with its practice and achieved results, as an instrument for the realization of predefined purposes. In this way are investigated not just the interfaces between Administrative Law, economics and political science, but mainly with management science. Therefore, the Administrative Law is metaphorically taken as a toolbox that brings together instruments with different capacities. Based on the new institutional economics, institutional legal design is focused as a way of guiding the selection, combination and management of Administrative Law tools according to the incentives they may generate to fulfill tasks as required. Administrative Law toolbox strategies are explored after faced with tools selection approach given by politics and public management, so establishing a diagnostic strategy to evaluate the consistency of legal arrangements in progress and a prognostic strategy to design tools combinations to produce adequate incentives. These strategies are leveraged through an association with methods of institutional experimentalism, incrementalism and minimalism. 


\section{KEYWORDS}

Administrative law - economics - politics - management - social technology - legal instrumentalism - toolbox - incentives - diagnostic - prognostic - experimentalism - incrementalism - institutional minimalism

\section{A caixa de ferramentas como uma metáfora pragmaticamente útil ao direito administrativo}

Tomando em conta a quantidade de órgãos e entidades existentes, e a quantidade de meios à disposição da administração para conformar os interesses públicos prioritários, empregar esses mecanismos para desenhar bons modelos tendentes a realizar o interesse público passou a ser uma questão central ao aprimoramento da gestão pública.

É que, ainda que assim muitas vezes o siga fazendo, o Estado de nosso tempo não deveria ser mais aquele que se pretendia provedor universal e tentava cuidar, de forma unitária, rígida e direta, de praticamente tudo da vida cotidiana, acreditando bastar-se a si próprio.

O Estado atual é multifacetado. Atua, paralelamente, de forma direta, indireta e associativa com a iniciativa privada, e tem tantas ferramentas à sua disposição para veicular seus programas, políticas e ações, que não precisa mais se reinventar e perder em grandes formulações. ${ }^{1}$ Nem ser social, nem absenteísta, ou assumir qualquer outro grande rótulo que o valha. $\mathrm{O}$ desafio pós-moderno do Estado é, sem abrir mão das conquistas democrático-constitucionais, ser eficiente. ${ }^{2}$ E ser eficiente implica conhecer e gerir melhor os instrumentos disponíveis, para assim otimizar seu emprego e, em uma análise prática, "resolver os problemas da vida". ${ }^{3}$

1 SALAMON, Lester M. The new governance and the tools of public action: an introduction. In: SALAMON, Lester M. The tools of government: a guide to the new governance. Nova York: Oxford University Press, 2002. p. 8.

2 BAPTISTA, Patrícia Ferreira. Transformações do direito administrativo. Rio de Janeiro: Renovar, 2003. p. 22-23; BINENBOJM, Gustavo. Prefácio. In: RAGAZZO, Carlos Emmanuel Joppert. Regulação jurídica, racionalidade econômica e saneamento básico. Rio de Janeiro: Renovar, 2011.

3 Devo a expressão coloquial a Marcos Juruena Villela Souto que, ao se deparar com alguma nova teorização jurídica ou construção interpretativa, recorrentemente se guiava pela máxima de que o direito existe para resolver os problemas da vida. 
Para superar esse desafio, é preciso repensar a forma de encarar e manejar o direito administrativo. O descompromisso na organização estrutural da administração pública, e o exercício da função administrativa, empunhando institutos de maneira desatenta e, por vezes, exclusivamente intuitiva quanto à sua capacidade de cumprir as finalidades que se pretende efetivar, não tem mais espaço hábil para seguir adiante.

Essa guinada, em favor da eficiência do Estado e da melhoria de sua gestão, passa, necessariamente, pela compreensão de que o direito administrativo, por força de seu desenvolvimento contínuo, dedicação a interesses múltiplos, caráter acumulativo, cultural, concreto e cotidiano, se transformou na compilação de uma grande diversidade de institutos e formas de organização com vocações próprias, ${ }^{4}$ que juntos integram uma verdadeira caixa de ferramentas voltada à instrumentalização de interesses públicos caso a caso. ${ }^{5}$

Com efeito, ferramentas são instrumentos vocacionados a certas finalidades. E apreender o direito administrativo como uma caixa delas é jogar luzes sobre a importância de se desenhar, escolher, combinar, empregar e testar essas ferramentas na persecução do interesse público, aprimorando a gestão pública e seu controle, a partir de juízos de adequação, experiência, e do acompanhamento e avaliação de resultados. ${ }^{6}$

Assim, há considerável utilidade prática em compreender e desenvolver, metaforicamente, o direito administrativo como uma caixa de ferramentas, no atual estado da arte em que se encontra. Especialmente tendo em vista que isso importa, a um só tempo, em:

(i) perceber o direito administrativo como uma tecnologia social, que deve cumprir uma função prática e dinâmica, a fim de dar conta de impasses e objetivos concretos;

(ii) caminhar na direção da construção de ideias e modelos jurídicos mais úteis e comprometidos com a realidade e seu contexto de aplicação, colaborando para a conciliação entre teoria e prática;

4 Salamon, "The new governance and the tools of public action: an introduction", op. cit., p. 1-2.

5 Christopher Hood e Helen Margetts tocam no ponto: "Podemos imaginar o governo como um conjunto de ferramentas administrativas - tais como ferramentas de marcenaria ou jardinagem, ou de qualquer outra atividade. [...] O que um governo faz para nós - seus súditos [subjects] ou cidadãos - é tentar moldar nossas vidas aplicando um conjunto de ferramentas administrativas, em várias combinações e contextos diferentes, de modo a servir a uma variedade de propósitos". HOOD, Christopher C.; MARGETTS, Helen Z. The tools of government in the digital age. Nova York: Palgrave MacMillan, 2007. p. 2.

6 PETERS, Guy B. Conclusion: the future of instruments research. In: ELIADIS, Pearl; HILL, Margaret M.; HOWLETT, Michael. Designing government: from instruments to governance. Quebec: McGill-Queen's University Press, 2005. p. 363. 
(iii) reforçar a relação de meios e fins que deve orientar a ação administrativa, ilustrando seu compromisso com os resultados concretos de suas reflexões;

(iv) não assumir categorias apriorísticas e estáticas, adotando em seu lugar uma abordagem constantemente crítica e flexível que, partindo do desenho das ferramentas, da forma como são utilizadas e da experiência acumulada, possa definir estratégias de ação e medir resultados e consequências daí provenientes;

(v) possibilitar o diagnóstico de como de fato funciona certa ferramenta, ou combinação de ferramentas, apurando suas vantagens e desvantagens para, então, formular, manter ou reformular o arranjo jurídico e a ação administrativa; e

(vi) experimentar novas ferramentas, de preferência pontualmente, para avaliar sua capacidade de sucesso em seus propósitos e, se assim confirmado, expandir sua incidência.

Desse modo, a abordagem da caixa de ferramentas é uma metáfora que privilegia o instrumentalismo legal enquanto estratégia de direito, para que as ferramentas de direito administrativo melhor sirvam aos fins democraticamente definidos na Constituição, ou pelas maiorias ocasionais, à luz da teoria dos direitos fundamentais.

Partindo dessa visão instrumental, o que se tem é um processo de diagnose e prognose, que deve ser contínuo e complementar, em prol do aperfeiçoamento do desenho e da combinação das instituições jurídicas para que cumpram suas funções. ${ }^{7}$

Em suma, a estratégia da caixa de ferramentas busca uma aplicação instrumental do direito administrativo com o propósito orientativo de encontrar, à luz da realidade, a eficiência de meios para melhor realização de fins substantivamente definidos.

É exatamente isso que espero com a metáfora do direito administrativo como caixa de ferramentas: enfatizar a investigação do método de manejo dos mecanismos jurídicos para endereçar questões de interesse público em concreto, superando a visão estática do direito administrativo como Estado, para pôr em seu lugar uma visão dinâmica, do direito administrativo enquanto um conjunto de arranjos jurídicos que geram incentivos endereçados a finalidades predefinidas.

7 Sobre as vantagens da caixa de ferramentas, ver: Hood e Margetts, The tools of government in the digital age, op. cit., p. 12 
Ao dessacralizar o direito administrativo, transformando-o em ferramenta social, como deve ser, pode ser possível colaborar para racionalizar o emprego de suas estratégias e institutos, em prol da melhora da gestão pública.

Nesse contexto, a fim de entender e propor acerca do direito como deveria ser, é preciso antes entender o direito como ele é. E não faço referência, aqui, à contraposição entre abordagens positivistas e normativistas. O direito como ele é precisa ser entendido como o direito ao modo pelo qual é utilizado por seus operadores, a partir dos incentivos que gera, e da maneira que o aplicam. O direito como deveria ser cuida de um novo sistema de incentivos, que, considerando fugas regulatórias e aprimorando desenhos, se aperfeiçoe de modo a tornar-se mais bem habilitado para alcançar os resultados desejados.

Ora bem, se o direito é praticamente empregado como ferramenta, ${ }^{8}$ ao invés de ignorar esse fato por ocasião de seu estudo, o melhor a fazer é justamente tomar o fato como premissa, assimilá-lo, buscando a aproximação entre teoria e prática para, como dito anteriormente, alcançar resultados mais proveitosos.

Pautada na eficiência e buscando o aprimoramento da gestão pública, a abordagem do direito administrativo enquanto caixa de ferramentas preocupa-se em aproximar a estruturação da administração pública e o exercício da função administrativa com os seus instrumentos, ${ }^{9}$ enfocando os arranjos jurídicos para repensar a forma de encarar e manejar o direito administrativo.

Nesse cenário, as ferramentas são (i) instrumentos dotados de recursos que podem ser identificados, (ii) assumindo a feição de instituições, gerando efeitos que oportunizam ou desincetivam condutas, e (iii) estruturando ações públicas dedicadas a realizar o interesse público.

Portanto, abordar o direito administrativo como uma caixa de ferramentas traz consigo o objetivo de desenhar bons modelos institucionais ${ }^{10}$ de ação administrativa, a partir da vocação própria de cada instituto jurídico e dos incentivos que são capazes de produzir, de modo a otimizar a efetivação do interesse público perseguido em concreto.

8 Carlos Ari Sundfeld, ao discorrer sobre os livros básicos de referência do direito, de uma forma geral, nota que o "estilo oculta sua principal função: a de caixa de ferramentas". SUNDFELD, Carlos Ari. Direito administrativo para céticos. 2. ed. São Paulo: Malheiros, 2014. p. 45.

9 Sobre a associação entre funções administrativas e instrumentos, ver: BUCCI, Maria Paula Dallari. Notas para uma metodologia jurídica de análise de políticas públicas. Fórum Administrativo - Direito Público - FA, Belo Horizonte, a. 9, n. 104, out. 2009. Disponível em: <http:// bid.editoraforum.com.br>. Acesso em: 2 fev. 2015.

10 Nesse sentido, ver: COUTINHO, Diogo R. O direito no desenvolvimento econômico. Revista Brasileira de Direito Público - RBDP, Belo Horizonte, a. 10, n. 38, p. 31-34, jul./set. 2012. 
Por ser comum adotar-se ferramentas que dificultam a gestão e a efetivação das finalidades pretendidas, ${ }^{11}$ numa visão pragmática, os esforços em selecionar as ferramentas para endereçar certa finalidade pública remontam à ideia de que há ferramentas que funcionam melhor do que outras, ${ }^{12}$ e é em busca de identificá-las, selecioná-las e combiná-las para o caso certo que se está.

Afinal, a concepção da ação pública reflete um momento estratégico, de modo que precisa ser elaborada a partir de esforços para encontrar os incentivos amoldados às finalidades pretendidas. ${ }^{13}$

Dessa maneira, toma especial realce utilizar a abordagem da caixa de ferramentas para:

(i) avaliar a adequação dos instrumentos empregados aos fins que se pretende efetivar;

(ii) a partir de sua lógica institucional e de incentivos, orientar a seleção e a combinação das ferramentas no momento de concepção, manutenção ou reformulação da ação administrativa; e

(iii) conferir certa manobra de conformação dos modelos institucionais, permitindo experimentos que possam ser incorporados à ação administrativa na medida em que se demonstrem bem-sucedidos. ${ }^{14}$

Os aportes trazidos pelos estudos de direito e economia, neste contexto, são fundamentais para auxiliar na compreensão. A abordagem econômica dos arranjos institucionais, pondo foco nos incentivos por eles gerados, tem por mérito principal incrementar a tomada de decisões jurídicas, à luz dos incentivos que as escolhas adotadas deverão produzir e, ao operador do direito em geral, permite entender melhor a lógica embutida aos comandos normativos, institutos e cláusulas contratuais.

Situado na interseção entre o direito e a economia, o enfoque do direito administrativo enquanto uma caixa de ferramentas é responsável por revelar os ganhos que a consideração de diretrizes econômicas, como uma das

11 SALAMON, Lester M. The tools approach and the new governance: conclusions and implications. In: Salamon, The tools of government, op. cit., p. 602.

12 RINGELING, Arthur B. European experience with tools of government. In: Salamon, The tools of government, op. cit., p. 593.

13 FREEMAN, Jody. Extending public law norms through privatization. Harvard Law Review, v. 116, p. 1341, 2002/2003.

14 COUTINHO, Diogo R. O direito nas políticas públicas. A ser publicado em MARQUES, Eduardo; FARIA, Carlos Aurélio Pimenta de (ed.) Política pública como campo disciplinar. São Paulo: Editora Unesp. Disponível em: <www.cebrap.org.br>. Acesso em: 17 fev. 2015. 
variáveis do plano jurídico, pode lhe trazer, auxiliando e otimizando suas tarefas e repercutindo em melhores resultados.

A seleção das ferramentas de direito administrativo deve ser resultado de um processo de formulação da ação administrativa que identifique as alternativas à disposição para, a partir delas, racionalmente comparar e escolher aquelas capazes de gerar os melhores incentivos em prol da realização do objetivo enfocado. Como as ferramentas de direito administrativo são mecanismos que incentivam condutas a finalidades predefinidas, o norte da ação administrativa, portanto, deve estar nos incentivos que essas ferramentas são capazes de produzir.

Essa lógica há de permear a ação administrativa como um todo, o que importa dizer que os incentivos funcionam como critério balizador, a um só tempo: (i) da escolha das ferramentas na formulação da ação administrativa; e (ii) do desenho e manutenção das instituições.

A lógica das instituições revela destacada utilidade ao direito, ao conferir uma leitura das regras e seus mecanismos de cumprimento enquanto instrumentos de restrição ou geração de oportunidades aos agentes, estruturando os incentivos para as relações travadas na sociedade.

Instituições são as regras do jogo em uma sociedade..$^{15}$ Elas importam porque os incentivos importam. E, no caso da ação pública, os incentivos são gerados pela escolha, modelagem, combinação e manuseio das ferramentas de direito administrativo. Desse modo, as ferramentas de direito administrativo integram parte significativa, e concreta, dessas regras do jogo, na medida em que efetivamente interferem na vida dos cidadãos, criando incentivos para orientar condutas, seja restringindo-as ou expandindo-as, por meio de oportunidades.

Uma síntese se faz possível. Instituições importam porque os incentivos importam. E as ferramentas de direito administrativo importam porque geram tais incentivos.

15 A famosa frase pertence a Douglass North: "Instituições são as regras do jogo em uma sociedade ou, mais formalmente, são os constrangimentos humanamente concebidos para configurar a interação humana". NORTH, Douglass. Institutions, institutional change and economic performance. Cambrige University Press, 1990. p. 3. Interessantemente, Gunther Teubner se aproxima dessa formulação ao apregoar: "O abandono do intervencionismo construtivista em favor do Direito em geral, segundo uma concepção do Direito como um conjunto de regras do jogo [law as a set of rules of the game] (Hayek, 1973; Hoppmann, 1972; Mestmäcker, 1978; see also Febbrajo supra)". TEUBNER, Gunther. After legal instrumentalism: strategic models of post-regulatory law. In: TEUBNER, Gunther. Dilemas of law in the welfare state. Berlim: Walter de Gruyter, European University Institute, Series A-Law 3, 1986. p. 307. 
A valiosidade das instituições, ferramentas e incentivos logo conduz ao desafio de propor e analisar as estratégias do direito administrativo como caixa de ferramentas.

Atentos à lógica de que o estudo dos instrumentos à disposição do governo para cumprir suas funções é fundamental para avançar no aperfeiçoamento desses meios de ação, é de longa data que cientistas políticos, economistas e gestores públicos têm se dedicado à análise das ferramentas sob esse viés. ${ }^{16}$

O direito, no entanto, tem passado quase ao largo da questão, em geral, tomando lugar apenas lateralmente nesse tipo de abordagem, sendo predominantemente manejado pela análise de legalidade das ferramentas escolhidas, sob a avaliação binária e estática de se certa iniciativa é permitida pelo ordenamento jurídico, ou não. Se é legal, ou ilegal. Em bom português: se "pode, ou não pode", sem maior compromisso com a busca de resultados práticos mais efetivos.

No entanto, a abordagem do próprio direito administrativo enquanto uma caixa de ferramentas, segundo a concepção instrumentalista, revela que ele é capaz de servir a bem mais que isso.

Com efeito, como os instrumentos de gestão estudados são, também, em sua maior medida, instrumentos disciplinados pelo direito administrativo, é primordial que os esforços da literatura jurídica especializada tomem parte desse tipo de análise dinâmica, em meio aos processos de formulação, avaliação e reforma da ação administrativa, indicando melhores caminhos sob a ótica da apreciação jurídica comparativa das instituições, ferramentas disponíveis e seus incentivos em potencial. Em síntese: é primordial que o manejo do direito administrativo permita indicar não só "se pode, ou não pode", mas vá além disso, oferecendo alternativas capazes de identificar "como se pode".

Para se engajar nesse desafio, é de especial interesse apresentar as estratégias que podem ser trilhadas pelo direito administrativo enquanto caixa de ferramentas.

Antes de individualizar o estudo dessas abordagens, contudo, vale situar a temática sob a ótica da política e da gestão pública, para que o espaço de contribuição do direito reste bem delimitado e, assim, forneça contribuições mais factíveis. Porque não adianta idealizar modelos jurídicos ótimos, mas

16 Há quem diga, inclusive, que essa tenha sido uma das mais significativas mudanças ocorridas na forma de fazer políticas públicas nos Estados Unidos, a partir da década de 1950. Ver, nesse sentido, SCHNEIDER, Anne; INGRAM, Helen. Behavioral assumptions of policy tools. The Journal of Politics, v. 52, Issue 2, p. 511, 1990. 
sem os pés no chão; que não tenham balizas de aplicação e, assim, sejam inatingíveis na prática, na medida de sua desconsideração à política e à gestão.

Qual é o melhor conjunto de ferramentas para endereçar certo objetivo público em dado contexto? Essa é uma pergunta dirigida principalmente aos gestores públicos, mas não só a eles, pois que para ser respondida com qualidade depende de boa análise político-administrativa e jurídica. ${ }^{17}$

De sua parte, o direito precisa entender essa lógica e replicá-la, adaptada, para o desenho dos arranjos jurídicos correspondentes. Isso permitirá sua otimização, bem como irá municiar gestores com mais massa crítica para fazerem frente aos desafios.

\section{Política, gestão pública e seleção de ferramentas}

A política e a gestão pública operam influências próprias na seleção das ferramentas de ação do governo. Por esse motivo é que, na sequência, me dedico ao papel e à abordagem de cada qual nesse contexto.

\section{II.1 A influência política na seleção de ferramentas}

No mundo real, o direito não é imune à política. A afirmação de Luís Roberto Barroso, ${ }^{18}$ ainda que originalmente formulada pensando na análise da separação de poderes à luz das interações entre o Poder Judiciário e outros atores políticos, se apresenta igualmente verdadeira no que toca à seleção de ferramentas para endereçar a ação pública. No mundo real, a seleção de ferramentas não é imune à política, e nem às partes interessadas que a influenciam.

Em matéria de seleção de ferramentas, a política se encontra com o direito em ao menos três ocasiões: (i) no momento normativo ordinário, definindo as ferramentas que serão disponibilizadas, e a quem o serão, à luz da Constituição; (ii) no momento de escolha entre as alternativas postas em sede ordinária ou constitucional, por decisão de autoridades superiores

17 A respeito da perspectiva dos formuladores de políticas públicas, e do incremento da qualidade dos modelos desenhados quando considerados o cenário político-administrativo e jurídico, ver RINGELING, Arthur B. Instruments in four: the elements of policy design. In: Eliadis, Hill e Howlett, Designing government, op. cit., p. 202.

18 BARROSO, Luís Roberto. Constituição, democracia e supremacia judicial: direito e política no Brasil contemporâneo. RFD - Revista da Faculdade de Direito - UERJ, v. 2, n. 21, jan./jun. 2012. 
da administração pública; e (iii) no momento do emprego, de fato, das ferramentas, por integrantes da burocracia estatal, ou administrados que tenham de escolher entre alternativas juridicamente estabelecidas.

Esse encontro põe em xeque o pretenso axioma segundo o qual as ferramentas são escolhidas por critérios exclusivamente técnicos ou de eficiência. Tanto que, em trabalho seminal realizado ainda na década de 1980, a pedido do Conselho Econômico do Canadá, um grupo de estudiosos capitaneado por Michael Trebilcock propôs, em lugar desses critérios, a adoção de um critério de escolha de ferramentas politicamente racional [politically rational instrument choice $]{ }^{19}$

Pois bem. Nos três momentos anteriormente referidos, a definição das ferramentas poderá ser influenciada, além da busca por realizar o interesse público em si: (i) pela ideologia dos agentes; (ii) por influência de grupos de interesse; (iii) pela maioria ocasional que elegeu seus representantes; e (iv) pelos interesses pessoais dos próprios agentes envolvidos ao longo do processo. $^{20}$

Para uma análise comprometida com a realidade, como aqui proposta, não é possível falar nas estratégias do direito administrativo enquanto caixa de ferramentas sem considerar a atividade dessas influências, até porque elas seguem surtindo efeito nos momentos subsequentes à modelagem do próprio arranjo de ferramentas. ${ }^{21}$

É certo que tais influências temperam a proposta de uma abordagem eficiente do direito, delimitando o espaço de manejo e seus instrumentos. Mas a política e todos os interesses que pode trazer consigo não conseguem chegar ao extremo de operar sem qualquer suporte de legitimidade, de modo que ao menos um verniz de interesse público haverá de estar presente para garantir aos agentes políticos a manutenção de suas posições de poder. Assim, a influência política tempera a abordagem da caixa de ferramentas, mas não a aniquila. A não ser que, do contrário, o desarranjo político seja tamanho, que nem mesmo nesse plano basilar se consiga alcançar os consensos mínimos sem os quais nada funciona; nem mesmo a própria política.

19 Ver TREBILCOCK, Michael J. et al. The choice of governing instrument. Economic Council of Canada's Regulatory Reference, 1982. Disponível em: <http://ssrn.com/abstract=1997355>. Acesso em: 15 out. 2015.

20 Ibid., p. 3.

${ }^{21}$ Sobre o tema, ver: Salamon, "The new governance and the tools of public action: an introduction", op. cit., p. 11. 
É preciso, pois, buscar o ponto ótimo entre a técnica, a eficiência, e a viabilidade política. ${ }^{22}$

A delimitação política do espaço de escolha das ferramentas faz com que o princípio da eficiência opere dentro desta arena, onde ainda é proveitoso o esforço de combinação e emprego das ferramentas à luz dos melhores incentivos que possam gerar.

Por outro lado, além de o desenho de escolhas eficientes poder se dar dentro das balizas definidas pela política, sendo entendido como um daqueles legalmente possíveis no contexto do que o ordenamento jurídico oferece (ex lege), a abordagem do direito administrativo como caixa de ferramentas também poderá ser manuseada para operar de forma persuasiva, na tentativa de, propositivamente, influenciar escolhas políticas e reformas (de lege ferenda).

Visto isso, para que a estratégia da caixa de ferramentas funcione bem, galgando resultados práticos efetivos, é preciso que ela se dê de maneira sempre contextual, pois uma boa avaliação do cenário político, econômico e administrativo será premissa determinante para o sucesso ou o insucesso de qualquer política pública orquestrada pelo governo. ${ }^{23}$

A política e as influências que transparece verdadeiramente exercem um papel nos arranjos de ferramentas de direito administrativo para endereçar interesses públicos. Mas, ainda assim, não se mantêm diante das circunstâncias, que podem ocasionar seu insucesso decorrente dos frágeis e equivocados incentivos gerados pelas instituições desenhadas, o que novamente indica para a necessidade de se buscar um ponto ótimo entre a viabilidade política, a técnica e a eficiência.

A par disso, o manejo do direito administrativo como caixa de ferramentas deverá estar atento ao contexto, e inevitavelmente receberá influências políticas que veiculem algum feixe de interesses próprios. ${ }^{24}$ Ainda assim, essa delimitação política terá de observar certa parcela de interesse público, a fim de assegurar sua legitimidade, garantindo a manutenção dos agentes políticos em suas posições e, portanto, à caixa de ferramentas restará um campo de atuação para buscar o arranjo mais eficiente e, num processo incremental, aprimorar a combinação de ferramentas que irá veicular a gestão pública, ou o

22 PETERS, B. Guy. The politics of tool choice. In: Salamon, The tools of government, op. cit., p. 557 e 563 .

23 Hood e Margetts, The tools of government in the digital age, op. cit., p. 149 e 151.

24 Neste sentido, ver: WEIMER, David L. Claiming races, broiler contracts, heresthetics and habits: ten concepts for policy design. Policy Sciences, n. 25, p. 373, 1992. 
papel de provocar a mudança, propondo arranjos e reformas que apresentem maior capacidade para realizar as finalidades pretendidas.

\section{II.2 A seleção de ferramentas segundo a gestão pública}

Assumindo a percepção de que já há muitos instrumentos à disposição da ação administrativa, e o importante agora seria aprimorar o seu desenho e emprego, estudiosos das políticas públicas, como Lester M. Salamon, relatam uma mudança na unidade de análise da administração pública e das políticas públicas, de uma abordagem centrada no órgão público, ou no programa público individualmente considerado, para uma abordagem focada nas ferramentas distintas por meio das quais se busca realizar os propósitos públicos da ação, justificando o desenvolvimento de uma abordagem de seleção de ferramentas (tool selection). ${ }^{25}$

A preocupação central da seleção de ferramentas sob a ótica da gestão pública consiste em promover o encaixe perfeito entre a ferramenta e a tarefa a cumprir, diante das diversas circunstâncias que se façam presentes. ${ }^{26}$ Trata-se de um objetivo que parte da premissa segundo a qual não existe um modelo universal (one size fits all) capaz de revelar a combinação pronta e acabada de ferramentas que funcionará diante de todo e qualquer cenário. Nesse sentido, nem estatização, privatização, regulação ou desregulação, por exemplo, seriam respostas preconcebidas bastantes a solucionar, individualmente, todo e qualquer problema. É que a escolha das ferramentas deve receber uma forte influência do contexto, e da finalidade que se pretende realizar, para ser bem-sucedida nesse propósito. ${ }^{27}$

Ciente disso, a literatura especializada dedicada ao tema passou a dirigir seus esforços analíticos para, em primeiro lugar, identificar as ferramentas e, em segundo lugar, estudar individualmente suas peculiaridades, do ponto de vista prático da gestão e de sua capacidade para resolver problemas concretos, por entender que essa aproximação da questão é uma forma mais produtiva de organizar esforços. ${ }^{28}$

25 Salamon, "The new governance and the tools of public action: an introduction", op. cit., p. 9.

26 Trebilcock et al., The choice of governing instrument, op. cit., p. 1.

27 Salamon, "The tools approach and the new governance", op. cit., p. 606.

28 HOWLETT, Michael. Designing public policies: principles and instruments. Londres e Nova York: Routledge Press, 2011. p. 24. 
Neste viés, portanto, é assimilado como ferramenta todo e qualquer mecanismo do qual o Estado possa se utilizar para cumprir suas finalidades: administração direta, regulação social, regulação econômica, terceirização, privatização, garantias, empréstimos diretos, garantias de empréstimos, seguros, incentivos fiscais, empresas estatais, consultas públicas, audiências públicas, autorizações, permissões, concessões, entre tantos outros.

Classificações dessas ferrramentas identificadas começaram então a ser propostas, fazendo surgir taxonomias que visam organizar sua compreensão. Não é meu propósito aqui aprofundá-las, mas para ilustrar registro as principais classificações e modelos de escolha de ferramentas. ${ }^{29}$

Christopher C. Hood classifica as ferramentas em duas dimensões principais: (i) a primeira delas se divide entre ferramentas de detecção, que são todas aquelas utilizadas pelo Estado para obter informações, e ferramentas de efetivação, que contemplam as ferramentas por meio das quais o Estado atua na tentativa de influenciar e conduzir o comportamento social; e (ii) a segunda dimensão, denominada pelo acrônimo NATO, cuida das ferramentas que instrumentalizam essa detecção, ou efetivação. Nelas, as ferramentas são agrupadas segundo quatro critérios: (a) nodalidade (propriedade de estar situada em meio a uma rede social de informações); (b) autoridade (relacionada com o exercício do poder de autoridade); (c) tesouro (relacionada com o emprego de recursos públicos); e (d) organização (relacionada com a existência de um corpo de agentes com quaisquer habilidades que sejam).$^{30}{ }^{31}$

De sua parte, Anne Schneider e Helen Ingram categorizam as ferramentas em cinco grupos, conforme o comportamento que os programas procuram modificar: (i) ferramentas de autoridade; (ii) ferramentas de incentivo; (iii) ferramentas de capacidade; (iv) ferramentas simbólicas ou exortatórias; e (v) ferramentas de aprendizagem. ${ }^{32}$

29 Abordagem mais detalhada pode ser encontrada em RIBEIRO, Leonardo Coelho. O direito administrativo como caixa de ferramentas. São Paulo: Malheiros, no prelo.

30 O esquema foi originalmente desenvolvido em HOOD, Christopher C. The tools of government. Londres: Macmillan, 1983; mas também pode ser encontrado em Hood e Margetts, The tools of government in the digital age, op. cit., p. 2-11.

31 Michael Howlett parte da proposta de Hood para inserir, entre as escolhas de ferramentas substantivas, também as escolhas de ferramentas procedimentais. Ver: Howlett, Designing public policies, op. cit., p. 51 e ss.

32 A abordagem é muito interessante e tem grande potencial para interagir com a regulação comportamental. Aprofundá-la em: Schneider e Ingram, "Behavioral assumptions of policy tools", op. cit., p. 527. 
Evert Vedung, alegoricamente, ordena as ferramentas referindo-se a elas como recompensas, punições ou sermões [carrots, sticks and sermons], ${ }^{33}$ que poderiam ser reconduzidas a ferramentas relacionadas com os planos jurídico, econômico e de comunicação, e se baseiam na força que cada uma dessas classes de ferramentas apresenta. ${ }^{34}$

Já Lester M. Salamon, por sua vez, dedica-se mais a um modelo de avaliação de ferramentas que seja capaz de orientar escolhas do que a propriamente classificá-las. Seguindo seu propósito, o autor identifica cinco critérios que devem orientar as escolhas de ferramentas, quais sejam: (i) efetividade; (ii) eficiência; (iii) equidade; (iv) gerenciabilidade; e (v) legitimidade/viabilidade política. ${ }^{35}$ A partir dessas considerações, seria então possível identificar melhor o que é mais importante na hora de escolher as ferramentas, de modo que tais critérios permitiriam maior clareza analítica nesse processo.

Visto isso, o autor elenca quatro dimensões-chave das ferramentas que devem ser levadas em consideração para sua escolha: (i) grau de coercibilidade; (ii) diretividade; (iii) automaticidade; e (iv) visibilidade. ${ }^{36}$

Diante dessas variadas aproximações acerca da escolha de instrumentos no campo das políticas públicas, Stephen Linder e Guy Peters se propõem a ordená-las em quatro grupos, de modo que haveria propostas de autores: (i) instrumentalistas, voltados a escolher uma ferramenta particular para cuidar de todas as questões; (ii) procedimentalistas, para quem a seleção de ferramentas resulta de ambientes políticos complexos, não sendo possível avaliar tais escolhas; (iii) contingencialistas, que veem a adequação do uso de ferramentas a depender dos tipos de tarefas; e (iv) constitutivistas, para quem a escolha de ferramentas "não é um simples exercício mecânico de adequação de problemas bem definidos e soluções igualmente bem definidas. Em vez disso, é fundamentalmente um processo de constituição de uma realidade para, então, trabalhar dentro dela". ${ }^{37}$

33 Em breve nota de tradução, a expressão "carrots and sticks" emprega a metáfora da cenoura como uma recompensa, e da "vareta" como uma punição, em alusão ao instrumento utilizado para encorajar o cavalo a se mover.

34 VEDUNG, Evert. Policy instruments: typologies and theories. In: BEMELMANS-VIDEC, Marie-Louise; RIST, Ray C.; VEDUNG, Evert Oskar. Carrots, sticks and sermons. Nova Jersey; Londres, 2003. p. 21-52.

35 Salamon, "The new governance and the tools of public action: an introduction", op. cit., p. 19 e ss.

36 Ibid., p. 26 e ss.

37 LINDER, Stephen H.; PETERS, Guy. The study of policy instruments: four schools of thought. In: PETERS, Guy; VAN NISPEN, Frans K. M. Public policy instruments: evaluating the tools of public administration. Cheltenham: Edward Elgar, 1998. p. 45. Ver Também: Hood e Margetts, The Tools of government in the digital age, op .cit., p. 170-171. 
Como se percebe, as teorias e classificações envolvendo a escolha de ferramentas e o desenho de políticas públicas passaram por diversas gerações, que foram incrementando esse processo, mas sempre compartilhando a premissa de que o design de políticas públicas e seus resultados são, em última análise, condicionados a fatores contemporâneos e à capacidade do Estado de enfrentá-los. ${ }^{38}$

A busca pelo que funciona e o que não funciona, e pelos motivos que levam a escolher determinada ferramenta entre várias disponíveis, definitivamente passou a ser um dos guias desta abordagem, primordialmente preocupada com o arranjo de políticas públicas. A saber, como as ferramentas são entre si substituíveis, ainda que umas possam alcançar melhores resultados que outras, o método primordial de investigação dessa seleção tem sido o de fazer análises comparativas entre as alternativas possíveis.

Ora, diante das muitas ferramentas disponíveis, e das variáveis presentes caso a caso, uma análise combinatória de todas as possibilidades de arranjo seria praticamente impossível, de modo que esse processo naturalmente segue a tônica de tentativa e erro; de acúmulo de experiências práticas (learn by doing), assimilação de resultados e relização de experimentos que, a partir do desempenho, possam seguir adiante, ser remodelados, ou abandonados. Com isso, confere-se bastante ênfase ao estudo do ciclo da política pública e suas fases de formulação e implementação, ${ }^{39}$ voltadas à escolha das ferramentas que, cada vez mais, deixam de ser abordadas sob a ótica individidual para serem investigadas sob a forma de combinações, ${ }^{40}$ tendo em vista os ambientes complexos e a interação que ocorre entre políticas públicas já existentes e novas políticas públicas. ${ }^{41}$

A gestão pública, portanto, dedica-se a conhecer as ferramentas à disposição, investigar como se relacionam, bem como entender as nuances da formulação e implementação de políticas públicas, acompanhando a concretização do modelo desenhado. ${ }^{42}$ Com essa finalidade, e tendo em vista o propósito jurídico de efetivar direitos que são veiculados pela ação administrativa,

38 Howlett, Designing public policies, op. cit., p. 140.

39 Howlett, Designing public policies, op. cit., p. 23-24.

40 Eliadis, Hill e Howlett, Designing government, op. cit., p. 7; e Howlett, Designing public policies, op. cit., p. 53.

41 Ponderando que um bom desenho de política pública é aquele que encaixa bem com os desenhos existentes, ver: GOODIN, Robert E. Institutions and their design. In: GOODIN, Robert E. The theory of institutional design. Nova York: Cambridge University Press, 1996.

42 Howlett, Designing public policies, op. cit., p. 139. 
a gestão pública deve interagir intensamente com o direito, de modo que eles possam se implicar mutuamente, trocando experiências e integrando a abordagem da caixa de ferramentas para gerar sistemas de incentivos mais adequados às finalidades pretendidas, como é o próposito da metáfora segundo os dois enfoques.

\section{As estratégias de aplicação do direito administrativo como caixa de ferramentas}

Apresentados os enfoques político e da gestão sobre a caixa de ferramentas que o governo tem a seu dispor para cumprir finalidades públicas, é agora possível abordá-la, sob o ponto de vista jurídico, dentro do espaço adequadamente delimitado que lhe cabe.

Como dito anteriormente, de sua parte, o direito precisa transpor a lógica da caixa de ferramentas para abordar o desenho dos arranjos jurídicos correspondentes, seja na hora de formulá-los ou revisitá-los, e não só sob a lógica bifronte da legalidade/ilegalidade, mas contribuindo ativamente com o desenho desses arranjos institucionais e dos incentivos por eles gerados, de modo a otimizar a ação pública. ${ }^{43}$

Pois bem. Partindo da ideia de que a "imagem da caixa de ferramentas oferece uma explicação tanto para o passado (poor design) quanto uma solução (better design)", ${ }^{44}$ a aplicação do direito administrativo como caixa de ferramentas pode se dar entre duas grandes abordagens: uma diagnóstica e outra prognóstica.

Diagnosticar é conduta que se dedica a identificar o problema em questão, enquanto prognosticar consiste na previsão, baseada em indícios, do que poderá acontecer se determinadas medidas forem adotadas.

Desse modo, o direito administrativo como caixa de ferramentas deve levar em conta o aprendizado retrospectivo, mas sem ossificá-lo, permanecendo flexivelmente aberto a inovações (experimentalismo) e à assimilação do aprendizado gerado pela prática, além de manter pretensões prospectivas,

43 Em sentido assemelhado, tomando por objeto de estudo as políticas públicas, ver: Bucci, "Notas para uma metodologia jurídica de análise de políticas públicas", op. cit.

44 Como formulado em: FISHER, Elizabeth. Unpacking the toolbox: or why the public/private divide is important in EC environmental law. Public Law and Legal Theory, Working Paper n. 35, Aug. 2001. 
concorrendo para o desenho dos incentivos destinados a um objetivo concreto (efetivar certo direito, implantar uma política pública, estimular uma conduta).

O aspecto retrospectivo das ferramentas colabora para o seu diagnóstico, analisando a compatibilidade entre instrumentos empregados (e seus incentivos) e fins almejados, de maneira a validar ou redirecionar os caminhos a seguir.

Já o aspecto prospectivo das ferramentas trabalha para incentivar condutas, partindo das alternativas institucionais disponíveis. Atua precipuamente na concepção da ação, seja ela original (nova política pública, v.g.) ou secundária (reforma de um marco regulatório, v.g.), em um esforço de prever o que deverá acontecer a partir desses incentivos.

No primeiro momento, desse modo, a lógica da caixa de ferramentas se alimenta da realidade (o que é), por meio da diagnose, justo para orientar a pauta do momento seguinte, de prognose, orientando a escolha dos meios mais habilitados para que o direito cumpra sua função prescritiva de condutas por meio de incentivos (o que deve ser).

Mais que isso, em matéria de direito administrativo, a estratégia da caixa de ferramentas deve incidir desde os macroarranjos, que distribuem competências, descentralizam ações e criam novas entidades, passando por arranjos intermediários, que escolhem os mecanismos que irão instrumentalizar a ação pública propriamente, como a regulação econômica, social, a terceirização, o financiamento e outros meios, até chegar nos microarranjos, delineando as características dos institutos em si, definindo se uma concessão de serviços públicos terá exclusividade ou não, se uma autorização de serviços públicos se dará por prazo determinado, ou indeterminado, e quais são seus requisitos, entre tantas outras nuances ao longo de todo esse processo, no qual interagem formuladores e executores, nos mais diversos níveis da administração pública.

Trata-se, portanto, de interagir com a formulação e a implantação da ação pública para municiá-la de modelos jurídicos que irão evitar ou mitigar dificuldades futuras, assim concorrendo para a viabilidade e o sucesso das medidas adotadas. ${ }^{45}$

Com efeito, as duas formas de aplicação são sempre comparativas - se avaliam vantagens e desvantagens das variáveis de cada ferramenta, em perspectiva entre as possíveis - , comprometidas com resultados práticos, e seguem a matriz instrumentalista que justifica a metáfora, segundo a qual:

45 MACDONALD, Roderick A. The swiss army knife of governance. In Eliadis, Hill e Howlett, Designing government, op. cit., p. 222. 
(i) não há máximas preconcebidas, de modo que, mesmo existindo uma ferramenta que possa ser a mais apta no caso, e a meta seja encontrála, as ferramentas são substituíveis, e é possível escolher entre várias delas para cada tarefa; ${ }^{46}$

(ii) a análise das ferramentas já empregadas deve enfocar as consequências práticas geradas, por força de seus incentivos, bem como a escolha das ferramentas, e de sua combinação, para hipóteses futuras, deve buscar antever os incentivos que dado arranjo de ferramentas poderá gerar; e, em qualquer dos casos, para ser bemsucedida;

(iii) a abordagem precisa considerar o contexto de manuseio da caixa de ferramentas; especialmente os contextos político e econômico, que podem ter influência determinante sobre seus resultados. ${ }^{47}$

Em uma remissão ao pragmatismo filosófico, que influencia o instrumentalismo jurídico, portanto, as formas de aplicação do direito administrativo como uma caixa de ferramentas devem ser antifundacionalista, consequencialista e contextualista, respectivamente. ${ }^{48}$

Feito esse apanhado geral, me dedico agora a investigar essas duas grandes estratégias de manuseio do direito administrativo, trazendo exemplos que possam traduzir sua utilidade prática e forma de emprego.

\section{III.1 A estratégia diagnóstica: a análise da compatibilidade entre ferramentas e finalidades a partir dos incentivos gerados}

A estratégia diagnóstica do direito administrativo como caixa de ferramentas se dedica a analisar os arranjos jurídicos existentes, à luz dos incentivos que produzem para atingir as finalidades pretendidas. Antes de mais nada, trata-se de uma análise da consistência jurídica desses arranjos para cumprirem suas finalidades. ${ }^{49}$

46 Ibid., p. 226.

$47 \quad$ Ibid., p. 207.

48 Sobre o tema, ver: POGREBINSCHI, Thamy. Pragmatismo: teoria social e prática. Rio de Janeiro: Relume Dumará, 2005; GODOY, Arnaldo Sampaio de Moraes. Introdução ao realismo jurídico norte-americano. Brasília: edição do autor, 2013; e MENDONÇA, José Vicente Santos de. Direito constitucional econômico: a intervenção do estado na economia à luz da razão pública e do pragmatismo. Belo Horizonte: Fórum, 2014.

49 Ao modo do que leciona Carlos Ari Sundfeld na seguinte passagem: "Ao tratar de operações econômicas, o direito administrativo dos negócios modela mecanismos (medidas, 
Esse exercício de avaliação do desenho das instituições como se encontram configuradas permite que, a partir daí, seja possível identificar os pontos da arquitetura jurídica que podem ser aprimorados, quando então entrará em cena - como veremos adiante - a subsequente e complementar abordagem prognóstica.

Pois bem. Para que o diagnóstico alcance seus objetivos, ele deverá se pautar em dois parâmetros principais que lhe poderão ser muito úteis, quais sejam: (i) a apuração da compatibilidade entre meios e fins; e (ii) a investigação da essência dos instrumentos empregados.

O parâmetro da averiguação da compatibilidade entre meios e fins se aproxima da ideia que é tipicamente veiculada pelo teste da proporcionalidade, e pode ser percebido, a rigor, como um teste pragmatista. ${ }^{50} \mathrm{Ou}$ seja: se a ferramenta escolhida não é adequada para cumprir determinada função, e os resultados por ela produzidos negam as finalidades às quais sua escolha e emprego remetem, isso conduzirá a um diagnóstico de que o desenho institucional precisa ser reformulado.

É que o princípio da eficiência, operante como postulado, interage com a proporcionalidade, a fim de checar a relação de intensidade entre os fins perseguidos pela administração e os meios empregados para atingi-los. Dessa maneira, ainda que não seja possível exigir a adoção do melhor meio de todos para realizar a finalidade pública identificada, seja pelo legislador, pelo regulador, ou pelo gestor público, simplesmente porque há várias ferramentas e combinações estratégicas concorrentes e viáveis, também não se pode permitir a adoção do meio menos intenso.

À vista disso, a incompatibilidade entre as ferramentas escolhidas para veicular determinada ação administrativa, e as finalidades que se pretende efetivar por meio delas, constituirá, prontamente, a hipótese de

instrumentos e organizações estatais). A questão, para a qual os juristas podem decisivamente contribuir, é a de saber da consistência jurídica dessa modelagem, isto é, o quanto as características de funcionamento desses mecanismos jurídicos permitem ou não que eles realizem os fins a que foram dirigidos". SUNDFELD, Carlos Ari. Direito público e regulação no Brasil. In: GUERRA, Sérgio (Org.) Regulação no Brasil: uma visão multidisciplinar. Rio de Janeiro: Editora FGV, 2014. p. 102.

50 Relacionando a qualidade das políticas públicas à adequação dos métodos utilizados, sob um viés de proporcionalidade, ver: Bucci, "Notas para uma metodologia jurídica de análise de políticas públicas", op. cit.; como argumenta José Vicente Santos de Mendonça: “Se assim for, o princípio da proporcionalidade como um todo é, essencialmente, um teste pragmatista, que serve para analisar as consequências das medidas, legais ou administrativas, tomadas pelo Estado". E, adiante, continua: "Se a verdade de uma proposição decorre da utilidade de suas consequências, então uma norma cujos resultados neguem seu propósito não ultrapassa o teste pragmatista". Mendonça, Direito constitucional econômico, op. cit., p. 113 e 114. 
menor intensidade no cumprimento do dever constitucional de eficiência, importando na quebra desse dever.

Nesse sentido, um campo extremamente fértil para a aplicação da abordagem diagnóstica do direito administrativo como caixa de ferramentas diz respeito à revisão do estoque regulatório (regulatory lookback). ${ }^{51}$

Com efeito, por força da profusão normativa, tanto ordinária quanto regulatória, e do próprio avanço das atividades reguladas, muitas exigências vão se acumulando ao longo do tempo, anacronicamente se mantendo vigentes sem maior utilidade, mas, ainda assim, implicando custos a seus destinatários e à máquina pública. ${ }^{52}$ Daí a aproximação diagnóstica desses arranjos, a fim de revê-los e remodelá-los, ou revogá-los, conforme sua efetividade e eficiência.

Por outro lado, sendo a ferramenta adotada compatível com a finalidade, será ainda possível constatar, a partir dos resultados concretos, se a arquitetura jurídica pode ser aprimorada ou não, aumentando sua eficiência. Além do que, a compatibilidade precisa ser apurada não apenas do ponto de vista da relação direta entre ferramenta escolhida/finalidade a concretizar, mas também sob o ângulo das ações públicas preexistentes para cuidar daquela mesma finalidade, de modo que o emprego da nova ferramenta seja coerente com a modelagem em operação, demonstrando aptidão para incrementá-la..$^{53}$

Em segundo lugar, ainda que os instrumentos não tenham uma única e estática finalidade, é preciso atentar para sua essência, evitando que sejam empregados em situações nas quais claramente não se encaixam. ${ }^{54}$

À primeira vista, pode parecer estranho formular um parâmetro nesses termos, mas a prática tem mostrado o quanto é comum que novas denominações sejam dadas para antigos institutos, bem como que ferramentas essencialmente carregadas de um certo conteúdo sejam empregadas em situações absolutamente descoladas de seus propósitos essenciais. ${ }^{55}$

Para a primeira hipótese, de confeccionar novas denominações a conteúdos já conhecidos, se deve atentar por que ela antes atrapalha, gerando

51 Sobre o tema, ver: SUNSTEIN, Cass. The regulatory lookback. Boston University Law Review, v. 94, p. 579-602, 2014; e RIBEIRO, Leonardo Coelho. Déficit público e revisão do estoque regulatório. Jota. 17 nov. 2015. Disponível em: <http://jota.uol.com.br/>.

52 HILL, Margaret. Tools as art. In: Eliadis, Hill e Howlett, Designing government, op. cit., p. 23.

53 Howlett, Designing public policies, op. cit., p. 145.

54 POSNER, Paul. Accountability challenges of third party governance. In: Salamon, The tools of government, op. cit., p. 533.

55 Salamon, "The new governance and the tools of public action: an introduction", op. cit., p. 22. 
incerteza e insegurança jurídica, e desperdiçando o conhecimento construído, do que oferece qualquer colaboração. ${ }^{56}$

Já para a segunda hipótese, de empregar ferramentas essencialmente carregadas de um certo conteúdo para fazer frente a situações descoladas de seus propósitos essenciais, o alerta se faz ainda maior, porque o emprego de um instrumento que não goza da aptidão para cumprir determinada finalidade emitirá os incentivos errados aos seus destinatários, e poderá importar não só no desperdício de recursos públicos escassos, mas também na perda de uma oportunidade valiosa para efetivar a finalidade pública pretendida, quebrando o dever de eficiência.

Ora bem, mesmo que respeitados esses dois parâmetros, a aproximação diagnóstica do direito administrativo como caixa de ferramentas permitirá também identificar a ocorrência de fugas regulatórias, ou seja, hipóteses nas quais os instrumentos escolhidos sejam aparentemente compatíveis com as finalidades pretendidas, sirvam essencialmente para tanto, mas não estejam, na prática, por questões contextuais políticas, administrativas, econômicas, culturais ou de legitimidade, sendo capazes de efetivar os objetivos perseguidos, tendo em vista os efeitos colaterais gerados por seus arranjos de incentivos.

Trata-se de um movimento natural, na medida em que é de se esperar que os destinatários da ação pública sempre ajam de maneira a se adaptarem aos incentivos gerados, utilitariamente tentando aumentar seus direitos e diminuir seus deveres, com a intenção de ampliarem seu patrimônio jurídico e, com ele, geralmente, o econômico também. Um exemplo vem a calhar.

Pense no regime jurídico dos servidores públicos, em linhas gerais. Da forma de ingresso, passando pelo exercício, e chegando à aposentadoria. Há incentivos inadequados para todo lado, e o resultado disso é um serviço custoso, burocrático, lento, ineficiente e descompromissado com os resultados.

Os concursos públicos para ingresso são excessivamente descentralizados, fragmentando a competição; não raro, em que pese serem exigentes, não conseguem aferir e treinar para aquilo que é necessário ao exercício da função administrativa; e os Poderes remuneram cargos equiparáveis de maneira diferente.

56 Para um exemplo, confira-se o debate acerca da nomenclatura dos ajustes celebrados entre entidades do Terceiro Setor e o poder público. Sobre o tema, confira-se: RIBEIRO, Leonardo Coelho. O novo marco regulatório do terceiro setor e a disciplina das parcerias entre organizações da sociedade civil e o poder público. Revista Brasileira de Direito Público - RBDP, Belo Horizonte, a. 13, n. 50, p. 95-110, jul./set. 2015. 
Os valores de remuneração são muitas vezes injustificadamente superiores a atividades semelhantes quando exercidas pela iniciativa privada, não se ligam a metas e, em algumas carreiras, como as jurídicas do primeiro escalão, já começam próximos ao teto remuneratório, desestimulando o aprimoramento e a progressão funcional.

Em geral, o tempo de serviço vale mais que a competência para alocar os servidores nas funções que devem ser desempenhadas, fazendo com que, aliás, mesmo naqueles casos em que os mais capacitados sejam também os mais experientes, e possam optar por sua alocação, eles o façam não para colaborar mais decisivamente para a efetivação do interesse público, mas pela função que os demandará menos, e irá remunerar da mesma forma.

A estabilidade, que tem o propósito de garantir a continuidade do serviço, protegendo-o de influências externas, tem produzido efeitos colaterais perversos, funcionando como um anteparo ao servidor descompromissado, que não quer exercer a função da forma correta, com a intensidade e a frequência necessárias, e nela encontra a garantia de que essa postura será tolerada. Uma espécie de fuga regulatória, portanto.

Há previsão de licenças, benefícios premiais e outros que, ainda que com bons propósitos, como o de aperfeiçoamento, dificilmente servem a esse fim, na prática.

Em síntese: a combinação das ferramentas de direito administrativo disposta para esse regime jurídico gera incentivos que resultam exatamente no avesso do que se diz pretender realizar. E o que isso tem despertado na população economicamente ativa do país não tem sido o pleito de mudança, mas o interesse individual em aderir a esse sistema. Com urgência, o tema precisa de debate, propostas e reforma, que desbordam os limites deste estudo. ${ }^{57}$

Pois bem. Especialmente em casos como este, de fuga regulatória, o emprego diagnóstico da caixa de ferramentas permitirá identificar essas fugas para que assim, no momento prognóstico complementar, seja possível remodelar a ação pública na tentativa de coibi-las, e fazer com que as condutas dos administrados retomem o curso esperado pela ação pública, e os resultados sejam mais bem alcançados.

A abordagem diagnóstica do direito administrativo como caixa de ferramentas, portanto, é capaz de analisar a compatibilidade entre ferramentas e

57 A este propósito, vale conferir o seguinte relatório de pesquisa: FONTAINHA, Fernando de Castro et al. Processos seletivos para a contratação de servidores públicos: Brasil, o país dos concursos? Relatório de pesquisa. Rio de Janeiro: Direito Rio, 2014. 
finalidades a partir dos incentivos que geram, e dos dados de realidade daí decorrentes, mostrando-se um poderoso instrumento de crítica e reavaliação dos arranjos estabelecidos, contribuindo com o primeiro passo para que as mudanças necessárias sejam feitas.

O passo seguinte fica a cargo da estratégia prognóstica, elaborada na sequência.

\section{III.2 A estratégia prognóstica: a escolha de ferramentas a partir da previsão de incentivos}

Ao mesmo modo como argumentado pelo pragmatismo filosófico, a abordagem prognóstica do direito administrativo como caixa de ferramentas deve se dar em relação à realidade atual, mas sempre projetando o futuro, ainda que dele não se possa ter certeza do que esperar. ${ }^{58} \mathrm{E}$ essa realidade atual, que servirá de ponto de partida, é justamente o produto resultante da abordagem diagnóstica vista anteriormente, que: (i) mapeia o arranjo jurídico posto; (ii) elenca os incentivos gerados; (iii) constata seus resultados; e então (iv) define os pontos que merecem aprimoramento para melhor realizar a finalidade pretendida.

Dessa maneira, em primeiro lugar, uma boa aplicação prognóstica do direito administrativo como caixa de ferramentas dependerá de um antecedente e preciso diagnóstico. ${ }^{59}$

Uma abordagem prognóstica inteiramente racional poderia ser procedimentalizada conforme o curso apontado por Christopher Hood e Helen Margetts: ${ }^{60}$

Convencionalmente, um formulador [chooser] deve adotar uma abordagem bem diferente se a intenção é qualificar a escolha como "racional". Formalmente, ele ou ela deve: (a) especificar o(s) objetivo(s) a ser(em)

58 Godoy, Introdução ao realismo jurídico norte-americano, op. cit., p. 30.

59 Como observado por Alice Bernardo Voronoff de Medeiros, ao se dedicar às falhas da regulação para então abordar sua otimização: "Não é possível construir prognósticos adequados se não há diagnóstico preciso". MEDEIROS, Alice Bernardo Voronoff de. Racionalidade e otimização regulatórias: um estudo a partir das falhas de regulação. Dissertação (mestrado) - Programa de Pós-Graduação em Direito da Universidade do Estado do Rio de Janeiro, Rio de Janeiro, 2012. p. 15.

60 Hood e Margetts, The tools of government in the digital age, op. cit., p. 146. 
alcançado(s); (b) identificar todas as formas ou meios possíveis pelos quais o objetivo pode ser alcançado; (c) determinar as prováveis consequências de cada alternativa; e (d) escolher a alternativa que provavelmente alcançará a(s) meta(s) com a maior certeza, na maior medida, ou com o mínimo de esforço.

Essas fases merecem ser detalhadas para refinar a abordagem.

Com efeito, definidos os objetivos a realizar, como que finalidade pública efetivar, ou qual arranjo de mecanismos reformar para aprimorar seus resultados, a estratégia prognóstica toma vez tanto na formulação de ações administrativas inéditas quanto na reformulação de programas já em curso. É por meio dela que se vão escolher e combinar as ferramentas de direito administrativo para resolver os problemas em concreto.

Nesse sentido, o enfoque prognóstico no manejo das ferramentas trabalha para incentivar condutas a partir das alternativas institucionais que o direito administrativo, enquanto caixa de ferramentas, disponibiliza. Trata-se, em síntese, de um esforço de prever o que deverá acontecer a partir desses incentivos.

Para isso, é preciso identificar as ferramentas e combinações disponíveis, bem como comparar sua capacidade de gerar os incentivos adequados.

Esse exercício comparativo deverá levar em consideração o conhecimento construído, que poderá dizer qual combinação de ferramentas costuma funcionar bem para determinada situação, ajudando a prever, com base em indícios, o que poderá acontecer caso sejam empregadas, e criando, assim, um banco de boas práticas cada vez mais apurado, mas nunca imutável. Afinal, a complexidade da tarefa, e as inúmeras variáveis circunstanciais que se farão presentes caso a caso impedem que a questão seja tratada segundo uma abordagem matemática que, automaticamente, receite uma estratégia " $\mathrm{A}$ " para um tipo de demanda " $\mathrm{B}$ ". ${ }^{61}$

Esse passo a passo, no entanto, raramente é respeitado na prática. Até mesmo por força da enormidade de combinações de ferramentas e alternativas possíveis, o que torna a tarefa mais que hercúlea, inviável.

Ainda assim, sua observância parcial, notável diante do estudo comparado de algumas alternativas possíveis e da coleta de parâmetros em ou-

61 BRESSERS, Hans TH. A.; O'TOOLE JR., Laurence J. Instrument selection and implementation in a networked context. In: Eliadis, Hill e Howlett, Designing government, op. cit., p. 132-153. 
tras experiências assemelhadas, pode colaborar para tornar o manejo desses instrumentos mais racional e eficiente. ${ }^{62}$

É que, como a política e o contexto, de maneira geral, importam e influenciam a escolha das ferramentas, o planejamento e a execução da ação pública não são, e nem podem ser, herméticos.

De toda forma, mesmo em caso de ausência de requisitos que se mostrem ideais para conceber a melhor medida possível, o esforço prognóstico poderá apontar critérios úteis ao propósito de racionalizar a ação pública diante das possibilidades dadas pela realidade (second best). ${ }^{63}$

A comparação de políticas públicas setoriais de saúde, educação e segurança, por exemplo, pode fazer com que se encontrem estratégias mais eficazes de efetivar direitos fundamentais do que o enfoque na exclusiva busca, pura e simples, de acesso e gozo individual a direitos, que tem causado judicialização excessiva e dificuldade sistêmica no Brasil. ${ }^{64}$ Com efeito, a instrumentalidade desse tipo de abordagem demonstra maior capacidade para cumprir as finalidades pretendidas do que uma abordagem substancial que dele se descuide.

Por saber, essa forma de análise institucional tem o potencial de entender a quais espécies de estímulos as pessoas respondem melhor e, com isso, orientar a formulação de arranjos jurídicos futuros a partir daí. ${ }^{65}$

Um bom exemplo para ilustrar a aplicação prognóstica de ferramentas de direito administrativo pode ser visto no campo do poder sancionador de entidades públicas e na arrecadação das multas administrativamente aplicadas a título de sanção.

Como é de conhecimento convencional, é cabível que a administração pública, por meio de uma manifestação imperativa que lhe é típica, aplique sanções aos administrados devido ao descumprimento de obrigações legais, regulatórias ou contratuais.

62 Hood e Margetts, The tools of government in the digital age, op. cit., p. 147.

63 A teoria do segundo melhor (second best theory) é uma teoria de origem econômica que recebe uma explicação técnica específica sob este ponto de vista. No entanto, também é comum referir-se a ela em outros meios para hipóteses nas quais todas as variáveis de um cenário ideal não se façam presentes e, portanto, assumir isso como premissa e identificar as variáveis envolvidas possa levar a melhores resultados, buscando-se soluções subótimas, assim consideradas as melhores entre as possíveis. A propósito do desenho de instituições à luz dessa teoria, ver: CORAM, Bruce Tabot. Second best theories and the implications for institutional design. In: Goodin, The theory of institutional design, op. cit., p. 101. Sobre a teoria econômica, ver: LANCASTER, Kelvin; LIPSEY, Richard G. The general theory of second best. The Review of Economics Studies, Londres, v. 24, n. 1, p. 11-32, 1957.

64 Bucci, "Notas para uma metodologia jurídica de análise de políticas públicas", op. cit.

65 Schneider e Ingram, "Behavioral assumptions of policy tools", op. cit., p. 525-526. 
Como as sanções não encontram fim em si mesmas, esse poder sancionador tem a função de transparecer um arranjo de incentivos negativos, por meio da sinalização de penalidades em caso de descumprimento de comandos previamente estabelecidos. Exatamente como se passa no caso da regulação do petróleo. No cumprimento da função de promover a regulação e a fiscalização das atividades econômicas integrantes da indústria do petróleo, balanceando os interesses em fricção no setor, a Agência Nacional do Petróleo (ANP) tem à sua disposição um poder sancionador para aplicar sanções administrativas e pecuniárias previstas em lei, regulamento ou contrato.

Até então, nada errado a respeito. Afinal, a previsão potencial de sanção é uma das ferramentas possíveis para incentivar condutas a finalidades preestabelecidas. Segundo sua lógica, espera-se que alguém não incorra em determinada conduta, sob pena de ser penalizado por isso.

Para funcionar bem, no entanto, esse arranjo de incentivos precisa ser analisado de uma perspectiva contextual.

Acontece que, como o arranjo institucional brasileiro afirma a inafastabilidade da tutela jurisdicional, não é raro que os efeitos da sanção administrativa, como meio para manter seu destinatário alinhado a certo objetivo de interesse público, se esvaiam diante de sua revisão pelo Poder Judiciário.

É que o arranjo institucional conformado pela não definitividade da decisão administrativa, somada à morosidade da prestação jurisdicional, faz com que aplicar sanções dificilmente efetive a finalidade de interesse público esperada.

A esse respeito, há notícia de que nos anos de 2011 e 2012, por exemplo, das multas aplicadas ao respectivo setor regulado, a Agência Nacional de Transportes Aquaviários (Antaq) recebeu 34\%, a Agência Nacional de Aviação Civil (Anac) recebeu 45,1\%, a Agência Nacional de Saúde Suplementar (ANS) recebeu 2,4\%, e a Agência Nacional de Telecomunicações (Anatel) recebeu $6,5 \% .66$

O Tribunal de Contas da União confirma esse cenário. Em levantamento relizado entre os anos de 2008 e 2011, para avaliar o resultado da arrecadação de multas aplicadas por 17 órgãos e entidades de regulação e fiscalização da administração pública federal, das mais de 997 mil multas aplicadas nos quatro anos, que somaram aproximadamente $\mathrm{R} \$ 29$ bilhões, foi possível arrecadar apenas $\mathrm{R} \$ 1,7$ bilhão. Uma proporção de $5,7 \%{ }^{67}$

66 Disponível em: <www.gazetadopovo.com.br>. Acesso em: 20 jul. 2015.

67 Disponível em: <www.tcu.gov.br>. Acesso em: 20 jul. 2015. 
Sem os recursos provenientes dessas penalidades: (i) os incentivos gerados pelo arranjo jurídico não conseguem cumprir sua função de melhorar a qualidade das atividades reguladas, finalidade última da sanção; (ii) é possível que os agentes regulados que cumprem suas obrigações e, portanto, não foram penalizados sejam colocados em posição concorrencial de desvantagem em relação àqueles que não cumpriram as obrigações, e nem tampouco arcaram com as correspondentes penalidades daí decorrentes; e (iii) a própria atividade fiscalizatória das agências e demais entidades de fiscalização fica comprometida, diante da carência de recursos para seu custeio. Em síntese: instala-se um ciclo vicioso e ineficiente, que desperdiça recursos, pode distorcer o mercado e não produz resultados práticos satisfatórios.

Diante dessas razões institucionais e pragmáticas, o campo de exercício de poder sancionador por entidades públicas também recebe os influxos do movimento de mudança de paradigmas do direito administrativo, que faz com que a imperatividade da ação administrativa ceda espaço a uma atuação mais consensual, concertada entre o público e o privado, quando comprovadamente se revele mais eficiente para cumprir as finalidades pretendidas.

Nesse contexto, uma ferramenta de direito administrativo que apresenta vantagens comparativas significativas à aplicação da sanção pura e simples, e pode melhorar os resultados práticos pretendidos, encontra-se nos chamados acordos substitutivos.

Os acordos substitutivos são instrumentos de composição celebrados em lugar da aplicação de uma sanção para, prospectivamente, suprirem a falta cometida por outros meios consensuais que não o cumprimento de uma pena, o que pode se dar mediante, por exemplo, a exigência de novos investimentos relacionados com o motivo da infração praticada. ${ }^{68}$ Trata-se de ferramenta disponibilizada a essas entidades por meio da do art. 5o, IV e §6º , da Lei no 7.347/1985, bem como, por vezes, em diversas disposições setoriais específicas.

Com isso, substitui-se o arranjo de incentivos negativos, característico das sanções, que se voltam à origem do conflito no passado, por um arranjo de

68 Sobre o tema, ver: MOREIRA NETO, Diogo de Figueiredo. Novos institutos consensuais da ação administrativa. Revista de Direito Administrativo - RDA, Rio de Janeiro, n. 231, jan./mar. 2003; MARQUES NETO, Floriano de Azevedo; CYMBALISTA, Tatiana Matiello. Os acordos substitutivos do procedimento sancionatório e da sanção. Revista Brasileira de Direito Público RBDP, Belo Horizonte, a. 8, n. 31, out./dez. 2010; SUNDFELD, Carlos Ari; CÂMARA, Jacintho Arruda. Acordos substitutivos nas sanções regulatórias. Revista de Direito Público da Economia - RDPE, Belo Horizonte, a. 9, n. 34, abr./jun. 2011; e PALMA, Juliana Bonacorsi de. Sanção e acordo na administração pública. São Paulo: Malheiros, 2015. 
incentivos positivos e apontado ao futuro, já que o agente regulado também tem interesse em investir em sua atividade para aprimorá-la, evitar novos descumprimentos e, possivelmente, obter maior lucro. ${ }^{69}$

Assim, em que pesem esses acordos substitutivos já serem utilizados atualmente, a adoção dessa ferramenta pode ser significativamente intensificada, já que, diante do sistema de incentivos postos pelo arranjo institucional atual, ela tende a produzir resultados práticos muito mais benéficos para o interesse público perseguido em concreto do que a aplicação imperativa de sanções que se revelam inefetivas. Tudo isso mediante um acompanhamento contínuo do bom funcionamento desse arranjo de incentivos.

Desse modo, a autoridade competente deverá, diante de um caso concreto: (i) apontar o objetivo a ser alcançado por meio da reprimenda ao ato infracional; (ii) identificar as ferramentas por meio das quais esse objetivo pode ser alcançado, estando entre elas a aplicação de sanção, ou a celebração de um acordo substitutivo; (iii) determinar as prováveis consequências de cada alternativa, ao modo como exemplificado anteriormente; e (iv) escolher a alternativa que provavelemente alcançará o objetivo com a maior certeza, na maior medida, ou com o mínimo de esforço.

Afinal, o que se deve ter aqui, por meio da estratégia prognóstica do direito administrativo como caixa de ferramentas, é um retroaprendizado empírico, que assimila e incorpora as medidas bem-sucedidas, descarta aquelas tentativas que se mostraram inaptas a realizar os objetivos pretendidos e se mantém aberto a novidades em potencial.

Ao conhecimento construído, que precisa permanecer flexivelmente mutável, é preciso acrescer inovações experimentais, que possam ser testadas e controladas para, então, disseminá-las.

Essa disseminação, por sua vez, deverá ocorrer preferencialmente de modo incremental, adicionando pequenas mudanças em sequência que, no conjunto, permitem correr menor risco de errar, além de tenderem a produzir resultados mais expressivos do que reformulações profundas feitas de uma só tacada. ${ }^{70}$ Exatamente como aconselham os métodos do experimentalismo, incrementalismo e minimalismo institucional, que complementam a abordagem da caixa de ferramentas e são agora apresentados.

69 Sobre o tema, no âmbito da regulação, ver: SOUTO, Marcos Juruena Villela. Direito administrativo em debate. Rio de Janeiro: Lumen Juris, 2004. p. 196-197.

70 Amparada na obra de Charles Lindblom, Maria Paula Dallari Bucci argumenta neste sentido. Ver: Bucci, "Notas para uma metodologia jurídica de análise de políticas públicas", op. cit. 


\section{O avanço das estratégias diagnóstica e prognóstica por experimentalismo, incrementalismo e minimalismo institucional}

As estratégias diagnóstica e prognóstica de direito administrativo, enquanto caixa de ferramentas, funcionam em um processo intercalado e contínuo, que poderá ser mais bem-sucedido se tais estratégias avançarem pautadas no experimentalismo, no incrementalismo e no minimalismo institucional.

O experimentalismo institucional consiste em um sistema fundado na valoração da experiência dentro de uma determinada prática científica.

Dessa maneira, assim como um cientista faria experiências para comprovar suas teses, arranjos jurídicos experimentais seriam adotados para testar o sucesso e efetividade da ação pública pretendida. $\mathrm{O}$ experimentalismo é, assim, entre outras coisas, uma prática de descoberta, análise e aprendizagem.

O experimentalismo pode ser reconduzido a estudos como o de Roberto Mangabeira Unger e Charles Sabel que, inspirados no trabalho de John Dewey, ${ }^{71}$ propõem que as políticas públicas sejam revisadas à luz da experiência prática. ${ }^{72}$

Nesse modelo, o Estado define objetivos e coordena diversas entidades que, de forma descentralizada, operarão em regimes colaborativos e participativos, capazes de aproveitar o aprendizado institucional obtido contextualmente. Trata-se, pois, de uma visão na qual as instituições são dinâmicas, e não estáticas, uma vez que os arranjos institucionais são experimentados e revisados continuamente. Desse modo, o experimentalismo se baseia em um aprendizado contextual, o qual fornece um insumo (input) para a remodelagem das políticas pelo governo. ${ }^{73}$

Segundo David Trubek, o experimentalismo institucional demanda a adoção de arranjos jurídicos experimentais em um setor específico da economia que possuam ao mesmo tempo estabilidade e flexibilidade. A estabilidade

71 Charles Sabel e William H. Simon reconhecem que a expressão é tomada da filosofia política de Dewey. Ver: SABEL, Charles; SIMON, William H. Minimalism and experimentalism in the administrative state. Columbia Public Law E Legal Theory Working Papers, Paper 9187, 2011. p. 26.

72 A expansão do método experimentalista para além das fronteiras do campo científico, ao campo dos estudos sociais, é abordada por Mangabeira Unger em: UNGER, Roberto Mangabeira. O direito e o futuro da democracia. Tradução de Caio Farah Rodriguez e Marcio Soares Grandchamp. São Paulo: Boitempo, 2004. p. 11.

73 Nesse sentido, ver: DEWEY, John. The public and its problems: an essay in political inquiry. University Park: Pennsylvania State University, 2012. p. 56-57. 
significa que, salvo a ocorrência de acontecimentos novos, o modelo que esteja fornecendo resultados positivos irá se manter. ${ }^{74}$ Por outro lado, a flexibilidade assegura que, à medida que a execução da política forneça ofeedback necessário, seja possível a fácil revisão dos arranjos estabelecidos.

Para procedimentalizar a abordagem, Charles F. Sabel e William H. Simon esquematizam o experimentalismo em quatro elementos básicos: (i) metas estruturais [framework goals] e parâmetros provisoriamente estabelecidos para verificar seu sucesso; (ii) outorga de ampla discricionariedade às unidades locais para perseguir seus fins de modo próprio; (iii) como condição dessa autonomia, tais unidades locais devem reportar regularmente seu desempenho e participar de uma revisão por pares, na qual os resultados são comparados com o de outras unidades que usam meios distintos para os mesmos fins; e (iv) metas, parâmetros e procedimentos de tomada de decisão devem ser periodicamente alterados de acordo com a resposta obtida no processo de revisão. Esse desenho institucional seria, então, o mais capaz de estimular a descentralização e o aprendizado na execução de ações públicas. ${ }^{75}$

O processo de experimentalismo institucional envolve, dessa forma, uma redefinição dos arranjos jurídicos e uma reorganização das ferramentas jurídicas para favorecer a experimentação de ações, no sentido de que elas sejam constantemente analisadas, de modo a se sujeitar a uma imediata e flexível revisão à luz das consequências observadas. ${ }^{76}$

Em síntese, isso implica um modelo político e regulador caracterizado pela flexibilidade e contingência. Seria, pois, uma mudança no modelo de comando e controle típico de modelos burocrático-administrativos em favor de abordagens menos rígidas e menos prescritivas. Mais precisamente, o experimentalismo coloca uma ênfase considerável na adaptação e promoção da diversidade de arranjos, dando importância à provisoriedade e revisibilidade desses arranjos e definindo soluções de acordo com a curva de aprendizado político. ${ }^{77}$

74 TRUBEK, David M. Developmental states and the legal order: towards a new political economy of development and law. University of Wisconsin Law School, Paper n. 1075, Feb. 2009. p. 20.

75 Sabel e Simon, "Minimalism and experimentalism in the administrative state", op. cit., p. 27.

76 Em sentido próximo, ver: ZANATTA, Rafael Augusto Ferreira. Direito, desenvolvimento $e$ experimentalismo democrático: um estudo sobre os papéis do direito nas políticas públicas de capital semente no Brasil. Dissertação (mestrado) - Universidade de São Paulo, São Paulo, 2014. p. 71.

77 Neste sentido, ver: PACHECO, Pedro Mercado. Experimentalismo democrático, nuevas formas de regulación y legitimación del derecho. Anales de la Cátedra Francisco Suárez, v. 46, p. 37-68, 2012. p. 45. 
A importância do emprego do método experimentalista às estratégias do direito administrativo enquanto caixa de ferramentas está no fato de que ele permite avaliar se os incentivos postos em prática por meio de um determinado arranjo institucional geraram, ou não, os efeitos que a aproximação prognóstica da caixa de ferramentas se propôs a produzir antes de a ação entrar em prática.

Por isso, experimentar ajuda a diagnosticar eventuais erros no arranjo jurídico proposto, devido ao uso equivocado de uma ferramenta que não se encaixou bem ao contexto ou à finalidade almejada. Além disso, permite valorar as consequências associadas a uma determinada ferramenta empregada, de modo a verificar sua adequação à finalidade perseguida. ${ }^{78}$

É bom que se diga: o Estado não se dá ao luxo quando promove experimentos. Justo o contrário. Trata-se de viabilizar a boa formatação das ações públicas, evitando que a ação geral e "definitiva" do Estado seja, ela própria, um grande experimento sem parâmetros prévios que, desse modo, põe tudo em teste, esboçando um grande potencial de riscos e prejuízos.

Em que pesem os possíveis benefícios de uma abordagem experimentalista, melhor ainda seria associá-la a métodos de incrementalismo e minimalismo, evitando, dessa maneira, rupturas abruptas e possibilitando, com as adequações pertinentes, replicar experimentos bem-sucedidos a outras hipóteses e esferas.

Aparentemente inspirado na mecânica social gradual de Karl Popper, ${ }^{79} \mathrm{O}$ incrementalismo consiste em um método de ação social proposto por Charles Lindblom, que: ${ }^{80}$

aceita a realidade existente como uma alternativa e compara as prováveis vantagens e desvantagens das alternativas intimamente relacionadas mediante pequenos ajustamentos da situação vigente ou faz ajustamentos maiores sobre cujas consequências aproximadamente tanto é conhecido como das consequências da realidade existente, ou ambos.

78 Ressalte-se que, nesse sentido, o experimentalismo se aproxima muito do denominado consequencialismo jurídico. Sobre consequencialismo jurídico, ver: ARGUELHES, Diego Werneck. Argumentos consequencialistas e estado de direito: subsídios para uma compatibilização. Disponível em: <www.conpedi.org.br>. Acesso em: 14 jul. 2015.

79 POPPER, Karl. A sociedade aberta e seus inimigos. Belo Horizonte: Itatiaia, 1974. v. 1, p. 172-175.

80 DAHL, Robert; LINDBLOM, Charles. Política, Economia e bem-estar social. Rio de Janeiro: Editora Lidador, 1971. p. 83-84. 
Segundo o incrementalismo, portanto, um sábio administrador deve selecionar cursos de ação de forma incremental, atuando por meio de pequenas e sucessivas mudanças, de modo a evitar que sejam produzidas consequências inesperadas e indesejáveis, já que "se ele prossegue através de uma sucessão de mudanças incrementais, ele evita graves erros" ${ }^{81}$

No lugar de transformações abruptas, nesse método, uma vez que os decisores se encontram limitados pela falta de informações, eles devem se mover bem devagar para reduzir suas chances de erro e permitir que ações corretivas possam ser tomadas. ${ }^{82}$ Essa abordagem refere-se a mudanças pequenas e não planejadas - na maioria das vezes - , as quais, paulatinamente, vão sendo implementadas. ${ }^{83}$

Por ser uma perspectiva mais realista, o incrementalismo prioriza um âmbito de atuação em micropolítica, onde são buscadas soluções para questões imediatas e pontuais. Daí Charles Lindblom afirmar que "a política pública não se faz de uma vez por todas; se faz e refaz sem cessar. A elaboração de políticas públicas é um processo de aproximações sucessivas a alguns objetivos desejados, que também vão mudando à luz de novas considerações" ${ }^{84}$

Dessa maneira, se o método incremental aponta a preferência pela mudança gradual e localizada, isso não quer dizer que mudanças maiores e mais rápidas sejam condenadas. Seja diante de casos em que a abordagem incremental não alcançará os fins necessários, ou de certas circunstâncias que favoreçam medidas mais robustas, será possível realizar mudanças maiores e mais rápidas. ${ }^{85}$

Por sua vez, o minimalismo, de forma semelhante ao incrementalismo, preconiza que eventuais modificações em políticas públicas devem ser feitas de forma localizada e gradativa. ${ }^{86}$

81 LINDBLOM, Charles E. The science of "muddling through". Public Administration Review, v. 19, n. 2, p. 86, Spring 1959.

82 A abordagem pode ser reconduzida ao pragmatismo, como registra Arnaldo Sampaio de Moraes Godoy em: Godoy, Introdução ao realismo jurídico norte-americano, op. cit., p. 30.

83 Lindblom, "The science of 'muddling through"', op. cit., p. 84.

84 Ibid., p. 86.

85 O ponto é desenvolvido por Robert Dahl e Charles Lindblom em: DAHL, Robert; LINDBLOM, Charles. Política, Economia e bem-estar social. Rio de Janeiro: Lidador, 1971. p. 84 e p. 85.

86 Sobre o tema, ver: GARCIA, Francisco. Minimalismo e incrementalismo constitucional. Revista Chilena de Derecho, Santiago, v. 41, n. 1, p. 27, abr. 2014. O termo está associado a Cass Sunstein e a sua leitura de como deve se dar a prestação jurisidicional. Aqui, no entanto, diz respeito à formulação da ação pública de modo eficiente e localizado. Ver: SUNSTEIN, Cass R. One case at a time: judicial minimalism on the supreme court. Massachusetts: Harvard University Press, 2001. 
Destarte, experimentar e incrementar permitem inovar sem causar insegurança jurídica e paralisia, como tanto ocorre no Brasil, e os exemplos não faltariam ao tema.

Ressalte-se, entretanto, que para o sucesso de qualquer das abordagens aqui pretendidas é importante dispor de sistemas ou estratégias de monitoramento que produzam informação útil, de modo a verificar se os resultados proporcionados pelas diferentes estratégias adotadas são maiores do que os custos para sua criação e operação.

Com isso, coloca-se em relevo a necessidade de processos de investigação e institucionalização das funções de monitoramento e avaliação, como parte integrante e indissociável da própria função de planejamento governamental.

A elaboração de uma estratégia de monitoramento em nosso país, entretanto, precisa avançar rumo a uma análise preocupada com a verificação da implementação e da eficácia da ação governamental, e não apenas pautada na mera apuração do cumprimento de obrigações formais e na prestação de contas. $^{87}$

No limite, as dificuldades para aprimorar a ação pública seguirão existindo, mas a associação das estratégias de direito administrativo como caixa de ferramentas à adoção do experimentalismo, do incrementalismo e do minimalismo institucional oferecem um arsenal argumentativo e analítico valioso, e que pode colaborar decisivamente para esse aprimoramento. ${ }^{88}$

\section{Conclusão}

Situadas diante dos contornos da política e da gestão pública - que já assimilaram a lógica da caixa de ferramentas na escolha de meios para endereçar as finalidades que se quer alcançar, de modo a racionalizar esse processo - as estratégias do direito administrativo como caixa de ferramentas revelam a capacidade de colaborar com o aprimoramento dos arranjos institucionais vigentes, e a formulação de novos arranjos. ${ }^{89}$

87 Como afirma Charles Sabel, para haver aprendizado sobre políticas públicas deve ser dado protagonismo na estruturação de práticas de monitoramento. Ver: SABEL, Charles. Learning by monitoring: the institutions of economic development. In: SMELSER, Neil J.; SWEDBERG, Richard (Ed.). The handbook of economic sociology. Princeton: Princeton University Press, 1994. p. 137-165.

88 Howlett, Designing public policies, op. cit., p. 146; Goodin, "Institutions and their design", op. cit., p. 42.

89 Como nota Arhur B. Ringeling, o direito toma parte desse processo na medida em que: “[...] As escolhas de instrumentos são o resultado de ideologia política, diferentes visões de governo 
Dessa maneira, sem abandonar a lógica jurídica tradicional, muitas vezes reduzida apenas a uma avaliação de legalidade/ilegalidade das questões concretas que se põem, assimilar o direito administrativo como caixa de ferramentas importa também em perceber seu papel-chave na consistência dos arranjos jurídicos para instrumentalizar os objetivos esperados, à luz dos incentivos que são capazes de produzir.

Nesse propósito, a abordagem do direito administrativo enquanto caixa de ferramentas, além de transparecer como funciona o manejo de institutos pelos operadores do direito na prática, cumpre o desafio de compreender juridicamente uma ação governamental e interagir para seu aprimoramento, ${ }^{90}$ o que faz por meio de duas estratégias principais, resumidas nas aproximações diagnóstica e prognóstica que complementarmente se sucedem e visam favorecer não só a eficiência pela eficiência, mas os objetivos finalísticos que medidas mais eficientes permitem melhor alcançar.

A estratégia diagnóstica se faz presente para avaliar combinações de ferramentas que se encontram em operação, avaliando sua compatibilidade com as finalidades a que se voltam, a partir dos resultados efetivamente gerados por seus incentivos.

Jogando luzes sobre relações inadequadas entre ferramentas e objetivos, ou mesmo fugas regulatórias em curso, ainda que diante de ferramentas teoricamente habilitadas, mas descreditadas por seus efeitos práticos no caso concreto, a estratégia diagnóstica tem o mérito de produzir, simultaneamente, análises críticas e pautas de ação a partir daí.

Identificados os objetivos, de seu lado, a estratégia prognóstica deve nortear a escolha das ferramentas entre as alternativas disponíveis, orientando-se pela projeção dos incentivos que provavelmente poderão produzir em concreto.

Para tanto, e sempre que a premência comportar, experimentalismo, incrementalismo e minimalismo institucional se apresentam como métodos de avanço seguro e consistente, testando arranjos jurídicos em ensaios monitorados e colhendo informações de seus resultados antes de replicá-los, incrementando ações em curso gradativamente e atacando as questões existentes preferencialmente de forma localizada.

e tradições jurídicas. Os instrumentos devem caber no cenário político-administrativo do país em particular". Ringeling, "Instruments in four", op. cit., p. 201.

90 Neste sentido, ver: Bucci, "Notas para uma metodologia jurídica de análise de políticas públicas", op. cit. 
Por meio de tudo isso, a abordagem do direito administrativo como caixa de ferramentas confirma sua instrumentalidade e compromisso com a realidade, se mantém aberta a inovações e aproxima teoria e prática no manejo do direito administrativo.

\section{Referências}

ARGUELHES, Diego Werneck. Argumentos consequencialistas e estado de direito: subsídios para uma compatibilização. Disponível em: <www.conpedi.org.br>. BAPTISTA, Patrícia Ferreira. Transformações do direito administrativo. Rio de Janeiro: Renovar, 2003.

BARROSO, Luís Roberto. Constituição, democracia e supremacia judicial: direito e política no Brasil contemporâneo. RFD - Revista da Faculdade de Direito - UERJ, v. 2, n. 21, jan./jun. 2012. Disponível em: <www.e-publicacoes. uerj.br/index.php/rfduerj/article/view/1794/2297>.

BINENBOJM, Gustavo. Prefácio. In: RAGAZZO, Carlos Emmanuel Joppert. Regulação jurídica, racionalidade econômica e saneamento básico. Rio de Janeiro: Renovar, 2011.

- Prefácio. In: ERLING, Marlos Lopes Godinho. Regulação do sistema financeiro nacional. São Paulo: Almedina, 2015. p. 7-9.

BRESSERS, Hans TH. A.; O'TOOLE JR., Laurence J. Instrument selection and implementation in a networked context. In: ELIADIS, Pearl; HILL, Margaret M.; HOWLETT, Michael. Designing government: from instruments to governance. Quebec: McGill-Queen's University Press, 2005. p. 132-153.

BUCCI, Maria Paula Dallari. Notas para uma metodologia jurídica de análise de políticas públicas. Fórum Administrativo - Direito Público - FA, Belo Horizonte, a. 9, n. 104, out. 2009. Disponível em: <www.bidforum.com.br/ PDI0006.aspx?pdiCntd=63051>. Acesso em: 28 jul. 2016.

CORAM, Bruce Tabot. Second best theories and the implications for institutional design. In: GOODIN, Robert E. The theory of institutional design. Cambridge University Press, 1996. p. 90-102.

COUTINHO, Diogo R. O direito no desenvolvimento econômico. Revista Brasileira de Direito Público - RBDP, Belo Horizonte, a. 10, n. 38, p. 31-34, jul./ set. 2012. 
. O direito nas políticas públicas. In: MARQUES, Eduardo; FARIA, Carlos Aurélio Pimenta de (Ed.). Política pública como campo disciplinar. São Paulo: Editora Unesp, no prelo.

DAHL, Robert; LINDBLOM, Charles. Política, Economia e bem-estar social. Rio de Janeiro: Lidador, 1971.

DEWEY, John. The essential Dewey: pragmatism, education, democracy. Indianapolis: Indiana University Press, 1998. v. 1.

. The public and its problems: an essay in political inquiry. Pennsylvania: Pennsylvania State University, 2012.

ELIADIS, Pearl; HILL, Margaret M.; HOWLETT, Michael. Designing government: from instruments to governance. Quebec: McGill-Queen's University Press, 2005.

FISHER, Elizabeth. Unpacking the toolbox: or why the public/private divide is important in EC environmental law. Public Law and Legal Theory. Working Paper n. 35, Aug. 2001.

FONTAINHA, Fernando de Castro et al. Processos seletivos para a contratação de servidores públicos: Brasil, o país dos concursos? Relatório de pesquisa. Rio de Janeiro: Direito Rio, 2014.

FREEMAN, Jody. Extending public law norms through privatization. Harvard Law Review, v. 116, p. 1285-1352, 2002-2003.

GARCIA, Francisco. Minimalismo e incrementalismo constitucional. Revista Chilena de Derecho, Santiago, v. 41, n. 1, abr. 2014.

GODOY, Arnaldo Sampaio de Moraes. Introdução ao realismo jurídico norteamericano. Brasília: edição do autor, 2013.

GOODIN, Robert E. Institutions and their design. In: GOODIN, Robert E. The theory of institutional design. Cambridge University Press, 1996. p. 1-53.

. The theory of institutional design. Nova York: Cambridge University Press, 1996.

HILL, Peter J. Public choice: a review. Faith E Economics, n. 34, p. 1-10, 1999.

HILL, Margaret. Tools as art. In: ELIADIS, Pearl; HILL, Margaret M.; HOWLETT, Michael. Designing government: from instruments to governance. Quebec: McGill-Queen's University Press, 2005. p. 21-30. 
HOOD, Christopher C.; MARGETTS, Helen Z. The tools of government in the digital age. Nova York: Palgrave MacMillan, 2007.

HOWLETT, Michael. Designing public policies: principles and instruments. Nova York; Londres: Routledge Press, 2011.

LANCASTER, Kelvin; LIPSEY, Richard G. The general theory of second best. The Review of Economics Studies, Londres, v. 24, n. 1, p. 11-32, 1957.

LINDER, Stephen H.; PETERS, Guy. The study of policy instruments: four schools of thought. In: PETERS, Guy; VAN NISPEN, Frans K. M. Public policy instruments: evaluating the tools of public administration. Cheltenham: Edward Elgar, 1998. p. 33-45.

LINDBLOM, Charles E. The science of "muddling through". Public Administration Review, v. 19, n. 2, p. 79-88, Spring 1959.

MACDONALD, Roderick A. The swiss army knife of governance. In: ELIADIS, Pearl; HILL, Margaret M.; HOWLETT, Michael. Designing government: from instruments to governance. Quebec: McGill-Queen's University Press, 2005. p. 203-241.

MARQUES NETO, Floriano de Azevedo; CYMBALISTA, Tatiana Matiello. Os acordos substitutivos do procedimento sancionatório e da sanção. Revista Brasileira de Direito Público - RBDP, Belo Horizonte, a. 8, n. 31, out./dez. 2010. Disponível em: <www.bidforum.com.br/PDI0006.aspx?pdiCntd=70888>. Acesso em: 28 jul. 2016.

MEDEIROS, Alice Bernardo Voronoff de. Racionalidade e otimização regulatórias: um estudo a partir das falhas de regulação. Dissertação (mestrado) Programa de Pós-Graduação em Direito, Universidade do Estado do Rio de Janeiro, Rio de Janeiro, 2012.

MENDONÇA, José Vicente Santos de. Direito constitucional econômico: a intervenção do estado na economia à luz da razão pública e do pragmatismo. Belo Horizonte: Fórum, 2014.

NORTH, Douglass. Institutions, institutional change and economic performance. Nova York: Cambrige University Press, 1990.

PACHECO, Pedro Mercado. Experimentalismo democrático, nuevas formas de regulación y legitimación del derecho. Anales de la Cátedra Francisco Suárez, v. 46, p. 37-68, 2012. 
PALMA, Juliana Bonacorsi de. Sanção e acordo na administração pública. São Paulo: Malheiros, 2015.

PETERS, B. Guy. Conclusion: the future of instruments research. In: ELIADIS, Pearl; HILL, Margaret M.; HOWLETT, Michael. Designing government: from instruments to governance. Quebec: McGill-Queen's University Press, 2005. p. 353-364.

. The politics of tool choice. In: SALAMON, Lester M. The tools of government: a guide to the new governance. Nov York: Oxford University Press, 2002. p. 552-564.

PETTIT, Philip. Institutional design and rational choice. In: GOODIN, Robert E. The theory of institutional design. Nova York: Cambridge University Press, 1996.

POGREBINSCHI, Thamy. Pragmatismo: teoria social e prática. Rio de Janeiro: Relume Dumará, 2005.

POPPER, Karl. A sociedade aberta e seus inimigos. Belo Horizonte: Itatiaia, 1974. v. 1.

POSNER, Paul. Accountability challenges of third party governance. In: SALAMON, Lester M. The tools of government: a guide to the new governance. Nova York: Oxford University Press, 2002. p. 523-551.

RIBEIRO, Leonardo Coelho. O direito administrativo como caixa de ferramentas. São Paulo: Malheiros, 2016. no prelo.

. O novo marco regulatório do terceiro setor e a disciplina das parcerias entre organizações da sociedade civil e o poder público. Revista Brasileira de Direito Público - RBDP, Belo Horizonte, a. 13, n. 50, p. 95-110, jul./set. 2015.

. Déficit público e revisão do estoque regulatório. Jota. 17 nov. 2015. Disponível em: <http://jota.uol.com.br/>.

RINGELING, Arthur B. European experience with tools of government. In: SALAMON, Lester M. The tools of government: a guide to the new governance. Nova York: Oxford University Press, 2002. p. 585-599.

. Instruments in four: the elements of policy design. In: ELIADIS, Pearl; HILL, Margaret M.; HOWLETT, Michael. Designing government: from instruments to governance. Quebec: McGill-Queen's University Press, 2005. p. 185-202. 
SABEL, Charles. Learning by monitoring: the institutions of economic development. In: SMELSER, Neil J.; SWEDBERG, Richard (Ed.). The handbook of economic sociology. Princeton: Princeton University Press, 1994.

SABEL, Charles; SIMON, William H. Minimalism and experimentalism in the administrative state. Columbia Public Law E Legal Theory Working Papers, Paper 9187, 2011.

SALAMON, Lester M. The new governance and the tools of public action: an introduction. In: SALAMON, Lester M. The tools of government: a guide to the new governance. Nova York: Oxford University Press, 2002. p. 1-47.

- The tools approach and the new governance: conclusions and implications. In: SALAMON, Lester M. The tools of government: a guide to the new governance. Nova York: Oxford University Press, 2002. p. 600-610.

SCHNEIDER, Anne; INGRAM, Helen. Behavioral assumptions of policy tools. The Journal of Politics, v. 52, Issue 2, p. 510-529, 1990.

SOUTO, Marcos Juruena Villela. Direito administrativo em debate. Rio de Janeiro: Lumen Juris, 2004.

SUNDFELD, Carlos Ari. Chega de axé no direito administrativo. Disponível em: $<$ www.brasilpost.com.br>.

. Direito administrativo para céticos. 2. ed. São Paulo: Malheiros, 2014.

. Direito público e regulação no Brasil. In: GUERRA, Sérgio (Org.). Regulação no Brasil: uma visão multidisciplinar. Rio de Janeiro: Editora FGV, 2014. p. 97-128.

. O direito administrativo entre os clips e os negócios. In: ARAGÃO, Alexandre Santos de; MARQUES NETO, Floriano de Azevedo (Coord.). Direito administrativo e seus novos paradigmas. Belo Horizonte: Fórum, 2008. p. 87-93.

SUNDFELD, Carlos Ari; CÂMARA, Jacintho Arruda. Acordos substitutivos nas sanções regulatórias. Revista de Direito Público da Economia - RDPE, Belo Horizonte, a. 9, n. 34, p. 133-151, abr./jun. 2011.

SUNSTEIN, Cass R. After the rights revolution: reconceiving the regulatory state. Cambridge: Harvard University Press, 1993.

. One case at a time: judicial minimalism on the Supreme Court. Massachusetts: Harvard University Press, 2001. 
. The regulatory lookback. Boston University Law Review, v. 94, p. 579-602, 2014.

TREBILCOCK. Michael J.t al. The choice of governing instrument. 1982. Economic Council of Canada's Regulatory Reference, 1982. Disponível em: <http://ssrn. com/abstract=1997355>. Acesso em: 15 out. 2015.

UNGER, Roberto Mangabeira. O direito e o futuro da democracia. Tradução de Caio Farah Rodriguez e Marcio Soares Grandchamp. São Paulo: Boitempo, 2004.

VEDUNG, Evert. Policy instruments: typologies and theories. In: BEMELMANS-VIDEC, Marie-Louise; RIST, Ray C.; VEDUNG, Evert Oskar. Carrots, sticks and sermons. Nova Jersey; Londres, 2003.

WEIMER, David L. Claiming races, broiler contracts, heresthetics and habits: ten concepts for policy design. Policy Sciences, n. 25, p. 135-159, 1992.

ZANATTA, Rafael Augusto Ferreira. Direito, desenvolvimento e experimentalismo democrático: um estudo sobre os papéis do direito nas políticas públicas de capital semente no Brasil. Dissertação (mestrado) - Universidade de São Paulo, São Paulo, 2014. 